International Journal of Research in Engineering and Innovation
(IJREI)
jJREI

\title{
Mapping of land use system in tegal city
}

\author{
Ginanjar Wiro Sasmito, M. Nishom
}

Department of Informatics Engineering, Polytechnic of Harapan Bersama, Tegal Indonesia

\begin{abstract}
The government of Tegal city doesn't currently have the media used to publicize land use, the socialization of land use is rarely done, so that this may cause some problems, such as: there is land used for facilities that are not, the efficiency of land use is not maximal, the existing public services in the city of Tegal become obstructed and inhibit the productivity of existing resources in the city of Tegal. Land Use Mapping System in Tegal City Area becomes a solution to the problems. The system is made based on the website that can be used as a media mapping of land use area contained in the city of Tegal. The system can also present comparisons of land use in the Tegal area of the city each year differently, in addition the system can also be updated easily.
\end{abstract}

Keywords: Mapping System, Land Use, Tegal City

(C) 2018 ijrei.com. All rights reserved

\section{Introduction}

A city is a large human settlemen [1] Cities generally have extensive systems for housing, transportation, sanitation, utilities, land use, and communication. City-dwellers have been a small proportion of humanity overall, but following two centuries of unprecedented and rapid urbanization, roughly half of the world population now lives in cities, which has had profound consequences for global sustainability [2]. One of the branches of urban planning is land use planning. Land use is a recurring process based on a dialogue between all the mutually negotiating stakeholders and who want a decision for sustainable land use in rural areas to initiate and monitor its implementation [3].

Land use is the human use of territory for economic, residential, recreational, conservational, and governmental purposes [4]. The concept of land use is closely intertwined with human community development. Patterns of human development and land use have shaped the environment locally and globally since prehistoric times. Current development patterns, together with features of the natural environment and the consequences of past development activities, determine future development opportunities, and also the need for restoration or enhancement of environmental resources [5].

The increasing diversity of urban activity attracts many people to try their fate in urban areas so as to heighten the flow of urbanization [6]. This resulted in a large demand for land supply to accommodate the increasing number of city dwellers. On the other hand, land is a very limited resource and can't be created or renewed, so the problem that often arises is the proliferation of slum and squatter areas in urban areas [7]. The unpreparedness of the city government in anticipating the growth and development of the city, especially in terms of population is also a major factor in the emergence of urban squatter and slums settlement areas, including those in Tegal. Tegal City is one of the cities located on the north coast road of Central Java. Located between $109^{\circ} 08^{\prime}$ '- $109^{\circ} 10^{\prime}$ East Longitude and $6^{\circ} 50$ '- $6^{\circ} 53^{\prime}$ South latitude, adjacent to Brebes regency in the west, Java Sea to the north, and Tegal regency in the east and south. Based on the Regional Regulation of Tegal City no. 2 Year 2004 on Spatial Planning of Tegal City, that the area of Tegal City is 3,968 Ha. Land use in the Tegal City area until 2014 based on the Regional Regulation is as follows:

1. Land for housing and development area of 1,954.2 Ha.

2. Land for Government Facilities / Public Service area of $34.2 \mathrm{Ha}$.

3. Land for Educational Facilities of 94.8.

4. Land for Health Facilities covering $13.92 \mathrm{Ha}$.

5. Land for Trading Facility of 256,6 Ha.

6. Land for Industrial Facilities of $91.83 \mathrm{Ha}$. 
7. Land for a Mixed Service Facility of $374.72 \mathrm{Ha}$.

8. Land for recreation facility / tourism area of $20 \mathrm{Ha}$.

9. Land for Agricultural Facilities of $857.7 \mathrm{Ha}$.

While the government of Tegal city does not have the media used to publicize land use in Tegal city, socialization of land use is rarely done, so this can cause some problems, including:

1. There is land used for facilities that are not as appropriate.

2. Optimization and efficiency of land use is not maximal.

3. Public services in the city of Tegal become obstructed.

4. Inhibit the productivity of existing resources in the Tegal city area.

These things can certainly hinder the progress of Tegal city, especially the city of Tegal plans to implement smart city that allows city officials to interact directly with both community and city infrastructure and to monitor what is happening in the city and how the city is evolving [8]. Therefore, a publication media with visualizing that is easily understood by the people of Tegal city is a cluster of land use mapping in Tegal city area that can be accessed and used easily by Tegal city community.

\section{Related Research}

Thanapura et al, 2006 in his research produced urban waste mapping using Quick Bird NDVI and GIS Spatial Modeling for Coefficient Runoff Detection. This study presents the integration of remote sensing and GIS to determine the runoff coefficient (C) recommended by the American Society of Civil Engineers and the Water Pollution Control Federation in 1969. $\mathrm{C}$ is a runoff index used as an input parameter in the most commonly used procedure: The rationale method for the calculation of runoff rainwater in small calculations on the urban watershed for the design and analysis of storm drainage. The purpose of this study was to evaluate 8-bit and 16-bit Quick-Bird (QB) NDVI satellite imagery using unsupervised classification and ISODATA algorithm to map the resistant and open spaces used for the determination of C in GIS spatial [9].

In a study conducted by Gao et al. 2008 has produced an online GIS Service for mapping and sharing of disease information. In the study, cases of infectious disease mapping were conducted in New Brunswick (Canada) and Maine (USA) to evaluate the architecture used, using Web Map Service standards, the Styled Layer Descriptor and Web Map Context specifications. The results show the effectiveness of infectious disease surveillance systems and enable the visualization, analysis, and sharing of infectious disease information through interactive and / or animated maps. Collaborating on multiple partners through a distributed network and a service-based architecture enables open and interactive collaboration of data and users sharing [10].

Chang et al, 2009 also conducts research on Google Earth and GIS Technology Combination for Dengue Fever Mapping in Developing Countries as a Monitoring System. In his research visual image of dengue fever case location, larval breeding and potential larval development sites used by dengue control specifically to prioritize the intervened environment in order to exercise targeted control. The results of this study are particularly suitable for limited control of resources as they utilize the available technology that does not depend on Internet access for everyday use and can be easily applied in many developing countries at a very small cost [11].

In a study conducted by Mas, 2004 has produced a mapping of land use / cover in tropical coastal areas using satellite sensor data, GIS and artificial neural networks. The problem with this research is to classify remote sensing images to map land use / cover on different lands that can cause errors during classification. Therefore, land use mapping procedures / include the incorporation of spectral information from recent images and data on the spatial distribution of land use types obtained from cartography and supplementary data. Two fuzzy maps, which show the membership of each usage class generated from the supporting and spectral data, respectively, using the artificial neural network approach. The combined maps are both obtained using the fuzzy rule [12].

Another similar study was also conducted by Brewer, 2006 on Basic Mapping as a Principle in Visualizing Cancer Data Using Geographic Information Systems (GIS). Cancer researchers can take advantage of mapping geographic information systems (GIS) as one of many existing tools and can broaden the symbolization approach used to investigate and illustrate existing data. Single map is one of the many possible data representations, so by making some maps a complete mapping business. The type of symbols, color choices, and data classifications each affect the information revealed by the map and best suit the characteristics of the particular data. Related data can be checked simultaneously with a coordinated classification and can also be compared using a multivariate symbol built on the basic rules of symbol design [13].

\section{Research Method}

\subsection{Research Framework}

Research Framework for the Design of Land Use Mapping System in Tegal City Region is shown in Figure 1. 


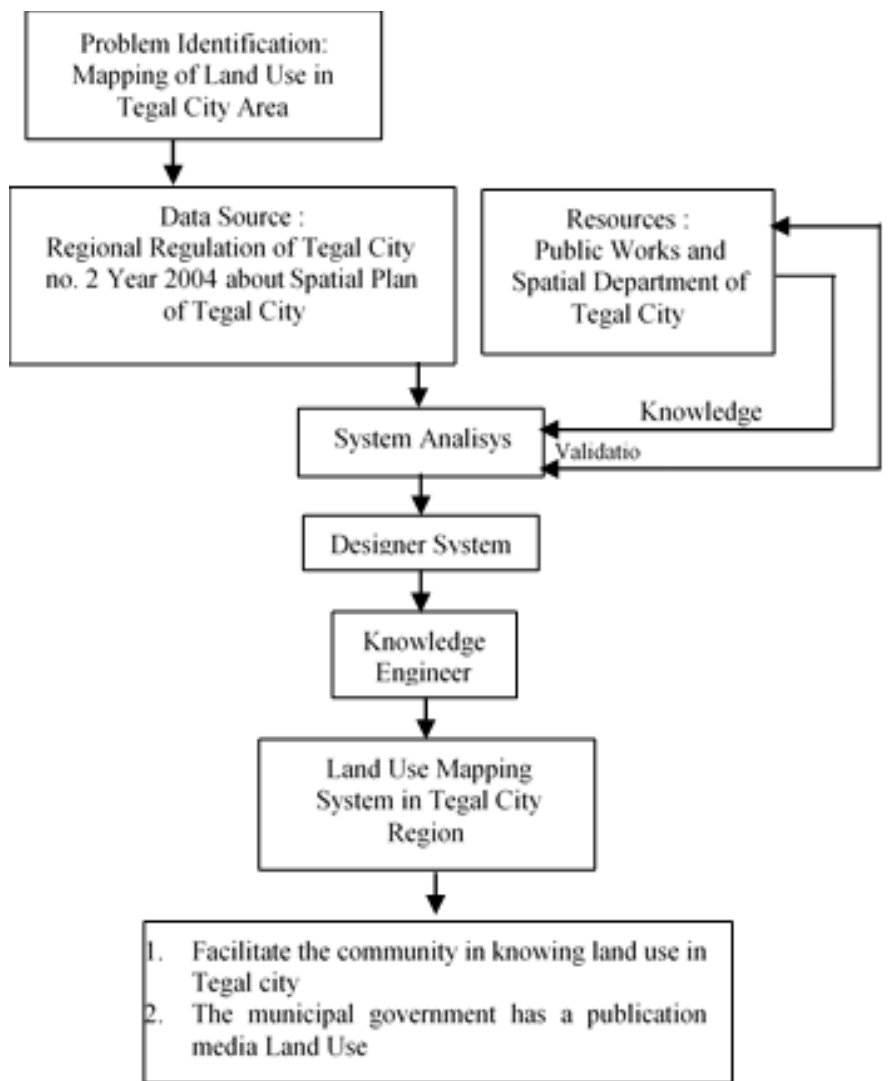

Figure 1: Research Framework of Land Use System

In making design implementation of land use mapping system that is by using Unified Modeling Language (UML). UML is a set of tools used to perform abstraction of an object-based system or software [14]. UML is a language used to define, visualize, build, and document when building systems with specific programming language codes. [15].

\subsection{Research Procedure}

This research was developed with Computer Based System Engineering method based on the principles of System Development Life Cycle with prototyping method. This prototyping method is also called Rapid Application Design because it simplifies and accelerates the system design [16]. Prototyping software or life cycle using prototyping is one method of system life cycle based on working model concept. The prototyping method scheme consists of: Initial Requirement, Prototyping, Prototyping Evaluation, System Development, Testing, System Evaluation and System Implementation.

\section{Result and Discussion}

\subsection{System Design}

The system design uses created using UML, it can be seen use case in Figure 2.

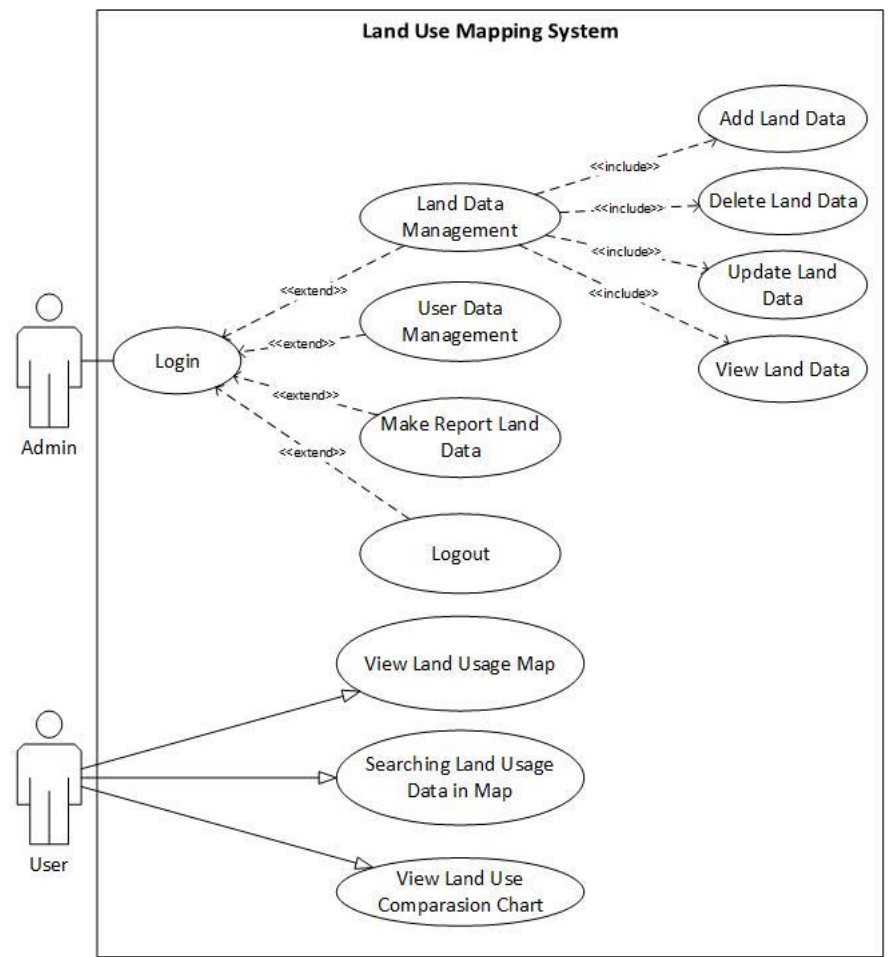

Figure 2 : Usecase Land Use Mapping System

\subsection{User Interface}

By using PHP programming language and MySQL database, implementation of mapping system of land use area of Tegal city has been successfully made. The results of the research have been in accordance with the menu shown in the figure 3 and 4.

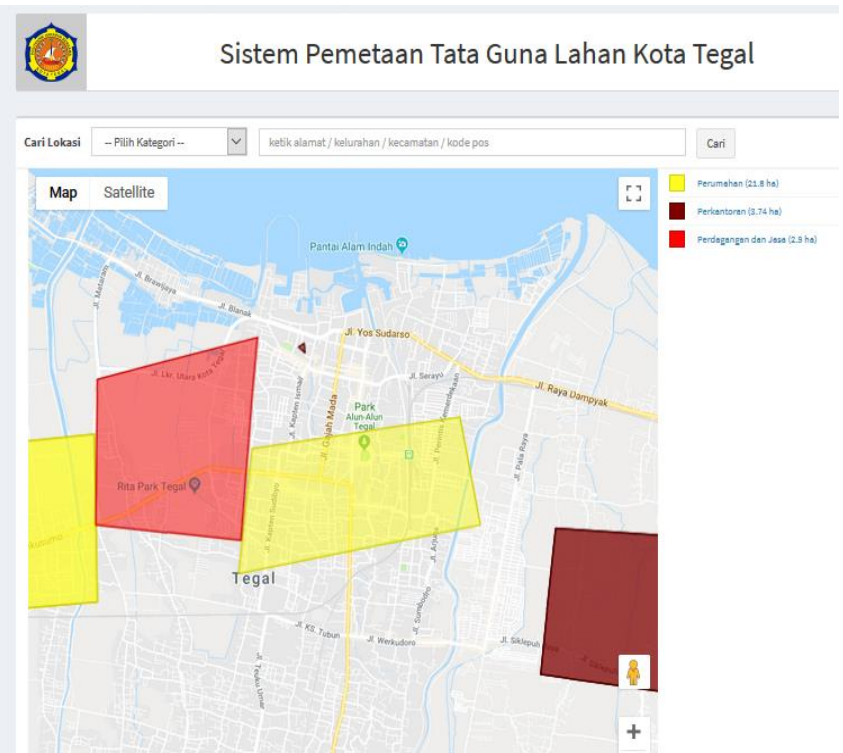

Figure 3 : Main Menu Land Use Mapping System [17] 


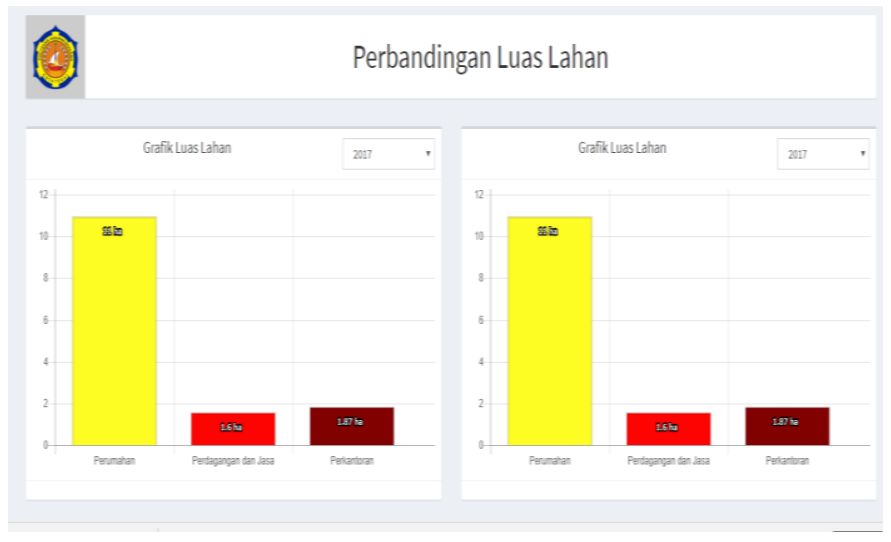

Figure 4: Graph Comparison Land area Menu [17]

\subsection{Discussion}

In prototyping method between user and system developer is always established a communication, user is always involved in every phase of system development, especially at the evaluation stage, both prototype evaluation and system evaluation, so that the developed system can be completed more quickly and completely in accordance with the needs and desires of the user.

In prototype evaluation phase, it is performed directly by the user, where the user can immediately determine whether the prototyping has been completed in accordance with wishes and needs of user or not. If it is appropriate then the next step can be done, namely by Encoding System (System Development). But if not, then Prototyping is fixed by repeating the Initial Requirement phase and Building Prototype (Prototyping) again.

\subsubsection{Coding System (System Development)}

This stage is where the prototype evaluation result of UML design and UI / UX design is translated by software engineer into a language understood by computer. Software Engineer in this stage translates the prototype evaluation results into programming codes. The result of this research is an application with platform of website, where application is built by applying back-end and front-end strategy. Backend is a page dedicated to admin to manage the website. While the front-end page is reserved for end-users. The programming language used in developing this application is PHP with My SQL as database.

\subsubsection{Testing}

In this research system testing is done by performing blackbox testing of all functions in the application. Black-box testing is one application testing or software that focuses on functional requirements of the software. Therefore black-box testing allows software developers to create a set of input conditions that will train all the functional requirements of a program.

\subsubsection{System Evaluation}

Evaluation of the system is done so that the system that has been produced really fit with the needs and can provide a solution to the existing problems. This phase is done before the results of the research is the application of this website is applied or in hosting. System evaluation is done directly by developers and users, where the user can immediately determine whether the system has been built in accordance with the wishes and needs or not. If it is appropriate then the next step can be done, i.e. with System Implementation. But if not, then the system has been built, improved by repeating the phase of System Encoding (System Development) and testing stage again.

\subsubsection{System Implementation}

Implementation of the system is the last stage in the prototyping method, this is done after the system evaluation has been completed. In this research, the making of land use mapping system is made using PHP programming language and My SQL database. The mapping system of land use is a website-based application that can be accessed when connected to the internet. Therefore in this phase is done a website hosting as a result of this research that has been done in order to be published.

Security mapping of land use system that has been generated in this research has fulfilled several aspects as follows:

a. Confidentiality: Efforts to safeguard information from unauthorized persons.

b. Privacy: is more towards data that is private.

c. Integrity: That information should not be changed without the permission of the owner of the information.

d. Authentication: Related to methods or means to assert that information is genuine and nothing can change if it has no right to change.

e. Availability: Associated with the availability of data and information when needed.

f. Access control: This aspect relates to the way access to information is arranged.

This is because the application has been equipped with a complete user id and password if will access the administrator menu.

\section{Conclusion}

Based on the results of research, it can be concluded as follows: Land use mapping system web base can be used as media mapping of land use area in the city of Tegal, beside this system can be considered for anyone in the development of the region in the city of Tegal. Then the system can present land 
use comparisons in the Tegal city area each year and administrators can easily sign land use, change and delete it on Tegal city map online.

\section{Reference}

[1] Kuper, A. and Kuper, J., eds (1996) The Social Science Encyclopedia. 2nd edition. London: Routledge.

[2] James, Paul; with Magee, Liam; Scerri, Andy; Steger, Manfred B. (2015). Urban Sustainability in Theory and Practice: Circles of Sustainability. London: Routledge.

[3] Amler B, Etke D, Eger H, Ehrich C, Kohler A, Kutter A, von Lossau A, Mu «ller U, Seidemann S, Steurer R, Zimmermann W. 1999. Land Use Planning: Methods, Strategies and Tools. Deutsche Gesellschaft für Technische Zusammenarbeit (GTZ) GmbH. Eschborn, Germany.

[4] Bureau of Land Management, U.S. Department of the Interior. Land Use Planning Handbook. March 11, 2005

[5] Corzine, John S., Governor and the Highlands Water Protection and Planning Council. Highlands Regional Master Plan State of New Jersey: November 2007.

[6] Barney Cohen (2015). "Urbanization, City Growth, and the New United Nations Development Agenda". 3 (2). Cornerstone, The Official Journal of the World Coal Industry. pp. 4-7.

[7] Ezeh, A., Oyebode, O., Satterthwaite, D., Chen, Y., Ndugwa, R., Sartori, J., et al. (2017), The history, geography, and sociology of slums and the health problems of people who live in slums The Lancet, 389(10068): 547-558. DOI: 10.1016/S0140-6736(16)31650-6.
[8] Peris-Ortiz, Marta; Bennett, Dag R.; Yábar, Diana Pérez-Bustamante (2016). Sustainable Smart Cities: Creating Spaces for Technological, Social and Business Development. Springer. ISBN 9783319408958

[9] Thanapura, Pravara, et all. 2006. Mapping Urban Land Cover Using QuickBird NDVI and GIS Spatial Modeling for Runoff Coefficient Determination. Photogrammetric Engineering \& Remote Sensing Vol. 73, No. 1, January 2007, pp. 057-065.

[10] Gao, Sheng et all. 2008. Online GIS services for mapping and sharing disease information. International Journal of Health Geographics 2008, 7:8 doi:10.1186/1476-072X-7-8.

[11] Chang, Aileen Y et all. 2009. Combining Google Earth and GIS mapping technologies in a dengue surveillance system for developing countries. International Journal of Health Geographics 2009, 8:49.

[12] Mas, J.F. 2004. Mapping land use/cover in a tropical coastal area using satellite sensor data, GIS and artificial neural networks. Estuarine, Coastal and Shelf Science 59 (2004) 219-230.

[13] Brewer, Cynthia. A. 2006. Basic Mapping Principles for Visualizing Cancer Data Using Geographic Information Systems (GIS). American Journal of Preventive Medicine. Published by Elsevier Inc. 07493797/06/

[14] Fowler, Martin.2004. UML Distilled (Third Edition). Pearson Education

[15] Mellor, Stephen J et all. 2002. Executable UML : A Foundation for Model Driven Architectures. Addison-Wesley Longman Publishing. USA

[16] O'Brien, James. A., 2005. Introduction to Information Systems.12th Edition. New York: McGraw-Hill.

[17] Sasmito, Ginanjar Wiro. 2018. Mapping Of Land Use System Tegal City. http://tatagunalahan.poltektegal.ac.id/ (August 31, 2018). 